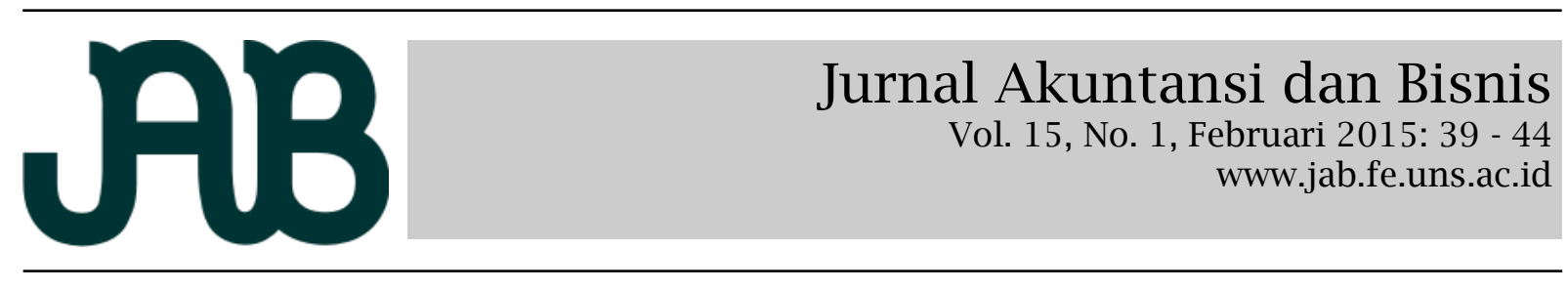

\title{
PENGARUH RISIKO KEUANGAN, DIVIDEND PAYOUT RATIO, DAN NILAI SAHAM TERHADAP PERATAAN LABA PADA PERUSAHAAN MANUFAKTUR DI BURSA EFEK INDONESIA (BEI)
}

\author{
RUFILA ISNA EL WAHYUNI
}

Universitas Islam Batik Surakarta

\begin{abstract}
A B S T R A C T
This study aims to determine the financial risk, dividend payout ratio and the value of stocks on income smoothing effect on manufacturing companies, especially in the field of food and beverage listed on the Indonesia Stock Exchange. The independent variables in this study is a financial risk, dividend payout ratio and the value of stocks, while the dependent variable of this research is income smoothing.

This study uses 10 manufacturing company engaged in the field of food and beverage and the teraftar in Indonesia Stock Exchange 2011-2014 period. This study uses a sampling technique used was purposive sampling method of testing this hypothesis using multiple linear regression analysis model to examine the effect of financial risk, dividend payout ratio and the value of stocks on income smoothing.

The results of this study examines the financial risk has no effect on income smoothing while the dividend payout ratio and the value of stocks significant influence on income smoothing.

Keywords: Financial Risk, Dividend Payout Ratio, Value Stocks, Income Smoothing

Penelitian ini bertujuan untuk menentukan pengaruh resiko keuangan, dividend payout ratio dan nilai saham terhadap income smoothing effect pada perusahaan manufaktur, khususnya di bidang makanan dan minuman yang terdaftar di Bursa Efek Indonesia. Variabel independen dalam penelitian ini adalah resiko keuangan, dividend payout ratio dan nilai saham, sedangkan variabel dependen dari penelitian ini adalah income smoothing.

Penelitian ini menggunakan 10 perusahaan manufaktur yang bergerak di bidang makanan dan minuman yang terdaftar di Bursa Efek Indonesia periode 2011-2014. Penelitian ini menggunakan purposive sampling sebagai teknik pengambilan sampel, pengujian hipotesis menggunakan model analisis regresi linier berganda untuk menguji pengaruh dari resiko keuangan, dividend payout ratio dan nilai saham terhadap income smoothing.

Hasil penelitian ini menunjukkan bahwa resiko keuangan tidak berpengaruh terhadap income smoothing, sedangkan dividend payout ratio dan nilai saham berpengaruh signifikan terhadap income smoothing.
\end{abstract}

Kata Kunci: Resiko keuangan, dividend payout ratio, nilai saham, income smoothing

\section{PENDAHULUAN}

Laporan keuangan dijadikan sebagai sarana terpenting untuk menyampaikan informasi keuangan agar dapat digunakan oleh pihak internal maupun eksternal perusahaan dalam pengambilan keputusan (Septiani 2015). Laporan keuangan juga dapat dijadikan skala untuk mengukur kinerja manajemen suatu perusahaan. Salah satu parameter yang digunakan untuk mengukur kinerja manajemen adalah laba

Industri jasa makanan dan minuman telah berkembang banyak, sesuai perhitungan itu melayani lebih dari 100 juta kali makan per hari. Hal ini telah menyebar di semua lapisan kehidupan mulai dari hotel, restoran, kantin industri, kantin rumah sakit, kereta api, saluran udara, semua kini menjadi bagian dari industri jasa makanan dan minuman. Fungsi dasar dari industri ini adalah untuk melayani makanan dan minuman untuk orang, untuk memenuhi berbagai jenis kebutuhan mereka. Tujuan utama adalah untuk mencapai kepuasan pelanggan. 
Perataan laba (income smoothing) dapat didefinisikan sebagai cara yang digunakan manajemen untuk mengurangi fluktuasi laba yang dilaporkan agar sesuai dengan target yang diinginkan baik secara artificial (tiruan) yaitu melalui pendekatan akuntansi maupun secara real yaitu melalui rekayasa transaksi (Koch 1981 dalam Merry 2006). Income smoothing mempunyai dua tipe yaitu income smoothing yang dilakukan secara sengaja oleh manajemen dan income smoothing yang terjadi secara alami. Income smoothing secara alami terjadi sebagai akibat dari proses menghasilkan suatu aliran laba yang merata, sementara income smoothing yang disengaja dapat terjadi.

Saham merupakan salah satu sekuritas yang diperdagangkan di pasar modal. Oleh karena itu, harga saham selalu mengalami fluktuasi naik dan turun dari waktu ke waktu yang lain. Risiko keuangan merupakan faktor selanjutnya yang diduga mempengaruhi manajemen untuk melakukan praktik perataan laba. Perusahaan yang memiliki risiko keuangan yang tinggi akan cenderung untuk melakukan praktik perataan laba untuk menghindari pelanggaran atas perjanjian hutang (Midiastuty 2003).

Dividend payout ratio juga merupakan salah satu faktor yang mempengaruhi praktik perataan laba. Kebijakan dividen perusahaan tergambar pada dividend payout ratio nya yaitu persentase laba yang dibagikan dalam bentuk deviden tunai, artinya besar kecilnya dividend payout ratio akan mempengaruhi keputusan investasi para pemegang saham dan disisi lain berpengaruh pada kondisi keuangan perusahaan.

Nilai saham juga dapat memicu timbulnya praktik perataan laba, karena laba yang stabil akan memicu ketertarikan investor terhadap saham perusahaan dan nantinya akan berpengaruh terhadap nilai saham perusahaan (Belkaouli 2007).

Tujuan penelitian ini adalah mengetahui pengaruh resiko keuangan, dividend payout ratio, nilai saham terhadap perataan laba pada perusahaan manufaktur yang terdaftar di Bursa Efek Indonesia.

\section{TINJAUAN PUSTAKA}

\section{Risiko Keuangan}

Leverage dapat diartikan sebagai penggunaan aktiva suatu dana. Semakin besar leverage menunjukkan bahwa dana yang disediakan oleh pemilik dalam membiayai investasi perusahaan semakin kecil, atau tingkat penggunaan utang yang dilakukan perusahaan semakin meningkat. Leverage dalam perusahaan meningkatkan laba perusahaan, tetapi jika terjadi sesuatu yang tidak sesuai, perusahaan akan mengalami kerugian dengan presentase laba atau bahkan mungkin saja lebih besar.

\section{Dividend Payout Ratio}

Dividend payout ratio menunjukkan besarnya deviden yang akan dibayarkan perusahaan dari total laba yang diperoleh perusahaan. Kebijakan dividen perusahaan tergambar pada dividend payout rationya yaitu persentase laba yang dibagikan dalam bentuk deviden tunai, artinya besar kecilnya dividend payout ratio akan mempengaruhi keputusan investasi para pemegang saham dan disisi lain berpengaruh pada kondisi keuangan perusahaan.

\section{Nilai Saham}

Nilai saham atau nilai perusahaan dapat diartikan sebagai kemampuan perusahaan dalam memaksimumkan kemakmuran pemegang saham. Nilai perusahaan dapat dicerminkan dalam harga saham perusahaan. Memaksimalkan nilai perusahaan berarti juga memaksimalkan kemakmuran pemegang saham yang merupakan tujuan utama perusahaan.

\section{Perataan Laba}

Perataan laba merupakan fenomena umum yang bertujuan untuk mengurangi variabilitas atas laba yang dilaporkan guna mengurangi resiko pasar atas saham perusahaan yang pada akhirnya dapat meningkatkan harga pasar perusahaan. Tindakan perataan laba ini telah dianggap tindakan yang logis dan rasional, namun bisa merugikan pihak lain. 


\section{METODE PENELITIAN \\ Populasi dan Sampel}

Populasi dalam penelitian ini adalah seluruh perusahaan manufaktur yang terdaftar di Bursa Efek Indonesia (BEI) dari tahun 2011-2014. Penelitian ini menggunakan teknik pengambilan sampel metode purposive sampling yaitu sampel dipilih berdasarkan kesesuaian karakteristik sampel dengan kriteria pemilihan sampel yang telah ditentukan.

\section{Jenis dan Sumber Data}

Penelitian ini merupakan penelitian kuantitatif, yaitu penelitian yang menekankan analisisnya pada data numerical (angka) yang diolah dengan metode nomerika. Untuk dapat melakukan pengukuran secara obyektif, maka setiap data dijabarkan kedalam beberapa komponen masalah, yaitu variable an indicator.

Sumber data peneltian yaitu sumber subjek dari tempat mana data bisa didapatkan atau diperoleh. Penelitian ini menggunakan sumber data sekunder. Data sekunder yaitu data penelitian yang didapatkan dengan tidak segera, dengan melewati media perantara atau didapatkan serta dicatat oleh pihak lain.

\section{Definisi Operasional dan Pengukuran Variabel}

\section{Risiko Keuangan (X1)}

Resiko keuangan diukur menggunakan rasio leverage yang berguna untuk menunjukkan kualitas kewajiban perusahaan serta berapa besar perbandingan antar kewajiban dengan aktiva perusahaan.

$$
\text { LEV }=\frac{\text { Total Hutang }}{\text { Total Aktiva }}
$$

\section{Dividend Payout Ratio (X2)}

Dividend payout ratio diukur dengan membandingkan dividen kas per lembar saham terhadap laba yang diperoleh per lembar saham.

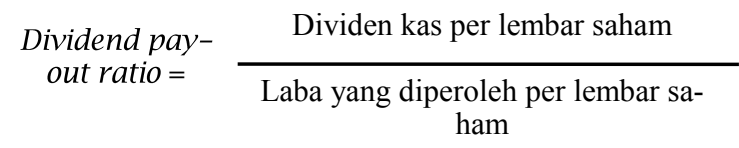

\section{Nilai Saham (X3)}

Nilai saham yang tinggi akan mencerminkan nilai perusahaan yang tinggi

Nilai Saham $=\frac{\text { Harga pasar saham }}{\text { Nilai Buku }}$

\section{Variabel Dependen}

Variabel dependen dalam penelitian ini adalah tindakan perataan laba.

$$
\text { Perataan Laba }=\frac{\mathrm{CV} \Delta \mathrm{I}}{\mathrm{CV} \Delta \mathrm{S}}
$$

Keterangan:

$\Delta \mathrm{I} \quad$ : Perubahan Laba dalam suatu periode

$\Delta \mathrm{S} \quad$ : Perubahan penjualan dalam suatu periode

CV : Koefisien variasi dari variabel yaitu standar deviasi dibagi dengan nilai yang diharapkan.

CVAI : Koefisien variasi untuk perubahan laba

$\mathrm{CV} \Delta \mathrm{S}$ : Koefisien variasi untuk perubahan pendapatan

$\mathrm{CV} \Delta \mathrm{I}$ atau $\mathrm{CV} \Delta \mathrm{S}$ dapat dihitung sebagai berikut :

$$
\begin{aligned}
& \mathrm{CV} \Delta \mathrm{S}=\frac{\text { Standar deviasi penjualan }}{\text { Rata-rata penjualan }} \\
& \mathrm{CV} \Delta \mathrm{I}=\quad \frac{\text { Standar deviasi laba operasi }}{\text { Rata-rata laba operasi }}
\end{aligned}
$$

\section{METODE ANALISIS DATA}

Penelitian ini menggunakan alat statistik regresi linear berganda dalam melakukan pengujian. Sebelum pengujian regresi linear berganda, peneliti sebelumnya melakukan uji asumsi klasik yang meliputi uji normalitas, uji multikolinearitas, uji heteroskedastisitas dan auto korelasi. Model regresi yang digunakan untuk mengetahui pengaruh variabel bebas terhadap variabel terikat dengan persamaan sebagai berikut:

$$
Y=a+b 1 X 1+b 2 X 2+b 3 X 3+e
$$

Keterangan :

$\mathrm{Y}=$ Dividend Payout Ratio (DPR)

$\mathrm{a} \quad=$ Konstanta 


$$
\begin{aligned}
& \mathrm{X} 1 \quad=\text { Cash Position }(C P) \\
& \mathrm{X} 2 \quad=\text { Debt to Equity Ratio }(\text { DER) } \\
& \mathrm{X} 3 \quad=\text { Return on Assets }(\text { ROA }) \\
& \mathrm{b} 1,2,3=\text { Koefisien regresi variabel X1,2,3 } \\
& \mathrm{e} \quad=\text { error }
\end{aligned}
$$

\section{ANALISIS DAN PEMBAHASAN Uji Regresi Parsial}

\section{Risiko Keuangan dan Perataan Laba}

Hasil pengujian t hitung untuk variabel risiko keuangan sebesar -0,011 dengan nilai signifikansi 0,992. Karena nilai $-\mathrm{t}$ table $<\mathrm{t}$ hitung $<\mathrm{t}$ table $(-1,687<-0,011<1,687)$ dan nilai signifikansi $>0,05(0,992>0,05)$. Hal ini dapat diartikan bahwa risiko keuangan tidak berpengaruh terhadap perataan laba. Sehingga risiko keuangan berpengaruh terhadap perataaan laba di tolak.

\section{Dividend Payout Ratio dan Perataan Laba}

Hasil pengujian menunjukkan bahwa t hitung untuk variabel dividend payout ratio sebesar 2,086 dengan nilai signifikansi 0,037. Karena nilai $-\mathrm{t}$ table $<\mathrm{t}$ hitung $<\mathrm{t}$ table $(-2,026<2,086<2,026)$ dan nilai signifikansi $<0,05(0,037<0,05)$. Sehingga dapat disimpulkan bahwa H1 diterima.

\section{Nilai Saham dan Perataan Laba}

Hasil pengujian menunjukkan bahwa t hitung untuk variabel nilai saham sebesar 2,576 dengan nilai signifikansi 0,004. Karena nilai $-\mathrm{t}$ table $<\mathrm{t}$ hitung $<\mathrm{t}$ table $(-2,026<$ $2,576<2,026)$ dan nilai signifikansi $<0,05$ $(0,004<0,05)$. Hal ini dapat disimpulkan bahwa semakin rendah nilai saham maka perusahaan memilih untuk melakukan pratik perataan laba. Sehingga penelitian menunjukkan bahwa nilai saham berpengaruh positif terhadap perataan laba.

\section{Uji Regresi Simultan (F)}

Hasil ini lebih besar jika dibandingkan dengan $\mathrm{F}$ tabel (pada df 1:38 diperoleh nilai F tabel $=1,74)$ dan nilai sig. 0,023 $<0,05$. Sehingga dapat disimpulkan bahwa dividend payout ratio dan nilai saham berpengaruh secara simultan terhadap perataan laba.

\section{Uji Koefisien Determinasi $\left(\mathrm{R}^{2}\right)$}

Nilai $\mathrm{R}^{2}$ digunakan untuk mengukur tingkat kemampuan model dalam menerangkan variasi variabel independen. Hasil perhitungan untuk nilai $R$ Square $\left(\mathrm{R}^{2}\right)$ dengan bantuan computer SPSS versi 17.00, diperoleh angka koefisien determinasi $\mathrm{R}^{2}=$ 0,602 atau $60,2 \%$.

\section{SIMPULAN}

Berdasarkan hasil analisis data maka diperoleh kesimpulan sebagai berikut:

a. Tindakan perataan laba terbukti dilakukan oleh beberapa perusahaan manufaktur yang bergerak di sektor food and beverage yang terdaftar di Bursa Efek Indonesia. Penelitian selama 4 tahun berturut-turut pada 10 perusahaan manufatur yang bergerak di sektor food and beverage

b. Hasil pengujian hipotesis memperlihatkan bahwa tidak terdapat pengaruh yang signifikan dari risiko keuangan terhadap perataan laba. Risiko keuangan mempunyai tingkat signfikan sebesar 0,992. Hal ini menunjukkan tingkat signifikansi jauh lebih besar dari 0,05.

c. Hasil pengujian hipotesis memperlihatkan bahwa terdapat pengaruh yang signifikan dari dividend payout ratio terhadap perataan laba. Dividend payout ratio mempunyai tingkat signifikan sebesar 0,037. Hal ini menunjukkan tingkat signifikansi jauh lebih kecil dari 0,05 .

d. Hasil pengujian hipotesis memperlihatkan bahwa terdapat pengaruh yang signifikan dari nilai saham terhadap perataan laba. nilai saham mempunyai tingkat signfikan sebesar 0,004. Hal ini menunjukkan tingkat signifikansi jauh lebih kecil dari 0,05.

\section{KETERBATASAN DAN SARAN}

Keterbatasan dalam penelitian ini yaitu kurangnya sampel yang hanya menggunakan 10 perusahaan manufaktur khususnya food and bavarage. Kemampuan variabel independen yang terdiri dari risiko keuangan, dividend payout ratio dan nilai saham mempunyai hasil penelitian 
$60,2 \%$ dan sisanya dipengaruhi oleh variabel lainnya.

Saran yang dapat peneliti berikan untuk penelitian selanjutnya diharapkan dapat menambah sampel penelitian serta menambah variabel lain selain risiko keuangan, dividend payout ratio dan nilai saham karena masih banyak sekali faktor lain yang mempengaruhi tindakan perataan laba.

\section{DAFTAR PUSTAKA}

Belkaouli, A.R. 2007. Accounting Theory. Jakarta: Salemba Empat.

Koch, B.S. 1981. Income Smoothing: An Experiment. The Accounting Review, (3): 574-586.

Merry. 2006. Pengaruh Harga Saham, Umur Perusahaan dan Rasio Profitabilitas Perusahaan terhadap Tindakan Perataan Laba. Skripsi, Program Studi Akuntansi, Universitas Andalas, Padang.
Midiastuty, S.D. 2003. Analisis Hubungan Kepemilikan, Nilai Perusahaan dan Investasi dengan Model Persamaan Linier Simultan.

Putra, A.J. 2014. Faktor-Faktor yang Berpengaruh terhadap Praktik Perataan Laba pada Perusahaan Manufaktur yang Terdaftar di Bursa Efek Indonesia Periode 2009 -2012. Bengkulu: Universitas Bengkulu.

Septiani, T.A. 2015. Pengaruh Tingkat Profitabilitas, Risiko Keuangan, Ukuran Perusahaan dan Nilai Perusahaan terhadap Perataan labapada perusahaan manufaktur yang terdaftar di Bursa Efek Indonesia Tahun 2009-2012. Skripsi, Universitas Muhammadiyah Surakarta, Surakarta.

Tandelilin, E. 2001. Analisis Investasi dan Manajemen Portofolio. Yogyakarta: BPFE. 
JURNAL AKUNTANSI \& BISNIS| Vol. 15, No. 1, Februari 2015: 39-44 